\title{
Long-Term Attachments and Complex Cognition in Birds and Humans are Linked to Pre-Reproductive Prosociality and Cooperation. Constructing a Hypothesis
}

\author{
Gisela Kaplan* \\ School of Science and Technology, University of New England, Armidale, Australia
}

\begin{abstract}
Human prosociality has often been regarded as an important step towards the capacity for empathy; i.e. to think of others in compassionate and caring ways. This ability, in turn, is related to social attachment. Many writers have rightly argued that, in order to understand the biology and evolution of social attachment, a comparative approach across many taxa is needed. Prosociality has been studied extensively in humans, non-human primates and some other mammals. Studies examining developmental stages and prosociality in altricial social birds are relatively sparse, of rather recent date and an altogether understudied area in avian behaviour and biology. The point of this paper is to report the discovery of a developmental social phase (and its cognitive and affective dimensions) in some long-lived avian species that is more than reminiscent of the development of prosocial behaviour in humans Based on this discovery; the paper develops a tentative hypothesis of pre-reproductive bonding/prosociality that can become the lynch-pin in mate-choice. Mate choice in birds, usually associated with physical features, is shown to be also based on individual personality and on social alliances that turn into social bonds well before the birds concerned reach sexual maturity. Such pre-sexual pair-bonding would be a particularly good adaption in preparation for long-term bonds and long periods of parenting, and it would contribute substantially to cooperative behaviour and, ultimately, to longevity. Similar to humans, birds are a vertebrate group whose strategies are based on long-term cooperative models and social attachments of parenting partners. In summary, it is suggested that mate-choice in long-lived, monogamous and largely monomorphic species may be foregrounded by a pre-sexual attachment to a potential mate. This mate-choice is thus not based on plumage or other external attributes. The questions of compatibility, personality and familiarity are discussed in detail as mechanisms that permit the expression of affiliations and attachments.
\end{abstract}

\section{Keywords}

Prosociality, Bonding, Attachment, Mate-choice, Social cognition

\section{Introduction}

In child psychology, prosocial behaviour refers to voluntary actions that are kind or helpful to others, according to 'Roots of Prosocial Behaviour in Children' [1]. Other researchers of child psychology and of forms of empathy in adults have defined prosociality as a spontaneous act of sharing or helping without expecting a favour, gift or beneficial action in return [2]. It can be a simple social act of assisting, approving or sharing treats. It may also refer to social mimicry, at times used interchangeably in the literature with prosocial behaviour [3]. Prosocial behaviour is meant to entail no losses to the giver while altruism is giving something that is a loss to the donor and of benefit only to the recipient. In human development, stages of prosocial behaviour have been clearly delineated, emerging in middle childhood, developing further in late childhood and reaching a peak in early adolescence [4]. Further, prosocial behaviour tends to increase during adolescence [5] and is regarded as a crucial transition period from childhood to adulthood [4]. It has been carefully examined in terms of developmental changes in the brain $[6,7]$, hormonal manipulations [8] as well as in terms of the social dynamics that may facilitate such behaviour [9], sometimes also referred to as "self-other-oriented resonance" [10]. Importantly, prosociality in human adolescence seems to require different neural circuits at different stages of development [7]. Increasingly, neuroimaging has been used to trace the devel-

*Corresponding author: Gisela Kaplan, School of Science and Technology, University of New England, Armidale, NSW- 2351, Australia

Accepted: July 28, 2020

Published online: July 30, 2020

Citation: Kaplan G (2020) Long-Term Attachments and Complex Cognition in Birds and Humans are Linked to Pre-Reproductive Prosociality and Cooperation. Constructing a Hypothesis. Ann Cogn Sci 4(1):127-142 
Citation: Kaplan G (2020) Long-Term Attachments and Complex Cognition in Birds and Humans are Linked to Pre-Reproductive Prosociality and Cooperation. Constructing a Hypothesis. Ann Cogn Sci 4(1):127-142

opment of traits such as reciprocity [11].

Prosocial behaviour is considered a desirable developmental outcome reflected in peer acceptance, whereas lack of prosocial behaviour has been associated with several neuro-developmental disorders $[6,7]$ and has thus remained very topical, evidenced by the recent devotion of an entire journal issue of Current Psychology to the human psychology of prosocial behaviour [12].

Importantly, implied in all studies on human behaviour is the understanding that humans are social animals, that there are protracted stages of childhood and adolescence and that such behaviour is built on complex cognitive and affective processes that determine future success in life generally and in partner choice specifically. While there is thus a good deal of research information on prosocial behaviour in humans available, and widely accepted, the suggestion of prosocial behaviour in animals is both a far more recent development and far less robust, less often documented and at times it is dismissed as a rubbery and possibly unscientific category. Indeed, it could be considered problematic to take over a very specific term for behaviour in humans and transpose it holus-bolus to animals. It has been done, however, starting, as so often, with examination of great apes, as the nearest relatives of humans, and then gradually being tested in lower primates, rats and other mammals.

While studies have tested prosocial behaviour in mammals [2] showing that some species seem to possess the capacity for spontaneous prosocial acts [13-15], one still needs to be careful when extracting a concept from its human context in which it may signify things that are embedded in cultural traditions and have specific symbolic value. Specific acts that are highly valued in human society as voluntary good acts (the good Samaritan syndrome [16]) may be adaptations in animals (requiring no decision making or specific moral compass). Moreover, in humans, internal events, thoughts and feelings can be communicated by language but are largely inaccessible to researchers of non-human animals. The chief aim in human studies has generally been to establish the evolutionary path of human altruism and empathy and the use of primates (from tamarins to great apes- (altogether some 15 species of primates) implicitly served largely to establish when prosocial behaviour emerged in the primate line as antecedents of human prosocial behaviour, sometimes focussing specifically on active and passive food sharing [17].

Increasingly, animal studies have taken up the challenge in more wide-ranging studies and across a variety of mammals. Well-controlled experiments were conducted in a range of mammals, from dogs [15] to primates [17], many such studies simply termed prosocial choice tests (PCT) [14]. In the restrictive environment of laboratories and the inability to do research using language and create complex social situations, avian studies were often confined to testing sharing and prosocial behaviour with food or tokens that could be exchanged for food later [18-20].

Thinking of their various ecological niches, wolves and wild dogs certainly share their food with offspring and members of the pack [21] as do most social carnivores, e.g. hyenas and lions [22]. However, many animals do not feed in ways that require any sharing. Indeed, both primates and birds, particularly those feeding on blossoms and fruit in trees or on insects or roots and grasses on the ground, space out so that each individual has a small foraging space on its own. To test food sharing outside their natural behaviour is likely to lead to unsatisfactory or ambiguous results. The motivation to share might exist but may belong to different domains, and to activities other than food-sharing (or exchanging tokens).

An excellent paper on the crucial issues in experimental studies of prosociality was published in 2016 [23], containing an extensive critique involving citation of 150 highly relevant research papers on prosocial experimental studies in non-human animals. The issues raised by the authors are astute and keep reminding us that comparative studies are not as simple as they appear. Some experiments ended up in disappointing, ambiguous and at times contradictory results and this has raised questions as to the applicability of such tests to animals and, in fact, this problem may be even more pertinent in the study of prosociality in birds [23]. The arguments of Marshall-Pescini, et al. [23] are as relevant today as they were in 2016. Here is not the place to recount all their arguments in detail. Suffice it to say that perhaps their most important comments concern the thoughts and considerations behind experimental designs as to whether animals are willing to share or help (i.e. exhibit prosocial behaviour) [23]. Among all experiments testing prosocial behaviour cited in their review [23], only five species were featured in avian studies testing prosocial behaviour; these were jackdaws, Corvus monedula [24-26], Eurasian jays, Garrulus glandarius [27,28], rooks, Corvus frugilegus [29], common ravens, Corvus corax [30,31] and the African grey parrot, Psittacus erithacus [32], i.e. four corvid species and one parrot, all known for their exceptionally advanced cognition [33].

For the purpose of this paper, the most important conclusion by Marshall-Pescini, et al. [23] is this. For future research they argued rightly that the design of experiments needs to take into account 1) The social organisation and social dynamics of each species and 2) Use follow up studies to see whether the most sharing individual donors and recipients eventually become pairs. The authors suggested that PCT (prosocial-choice test) paradigms be considered in a group setting, where animals have the freedom to choose which partner to provision [33]. These two points, particularly the second point, is at the basis of the argument in this paper.

In brief, this paper will argue that prosocial behaviour in birds may occur in very specific species at a very specific time and signify important developmental milestones that may both be time-sensitive and be subject to social and ecological influences that which then foster or constrain its expression. Furthermore, there needs to be physiological, hormonal and other biological evidence that make the evolution and expression of prosocial behaviour even possible. Furthermore, such prosocial behaviour tends to reveal its distinct advantage in, and preparedness for close bonds and ultimately for successful mate-choice.

Its evolution, it is suggested here, might well have aris- 


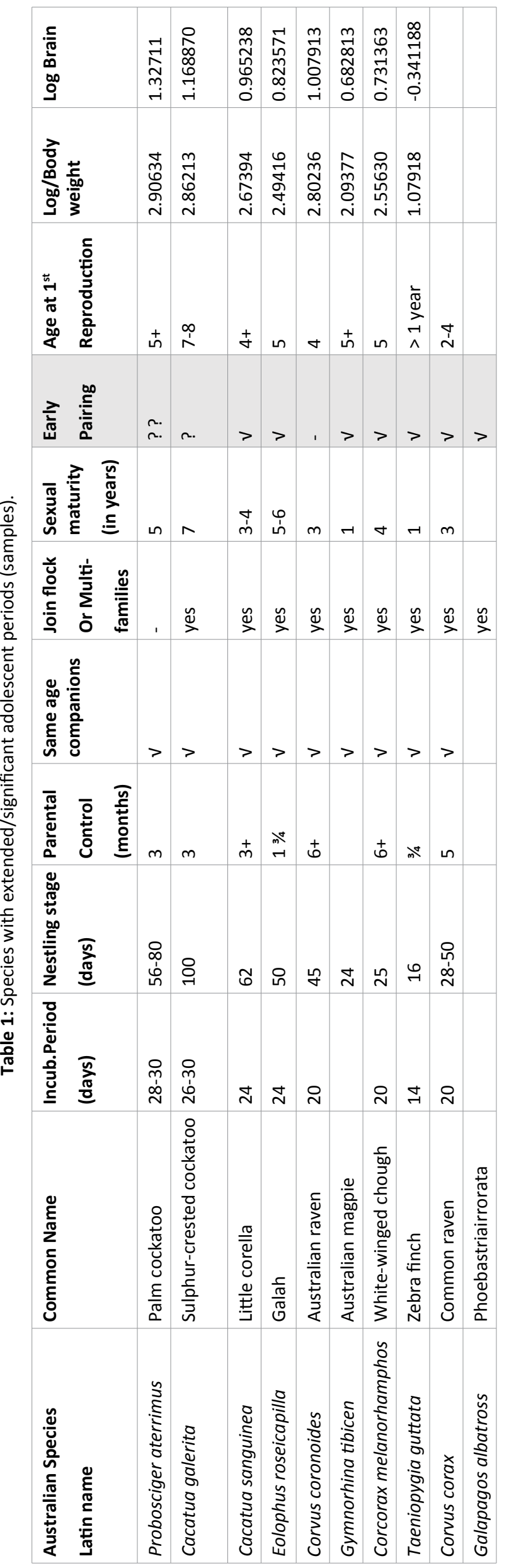

en as a result of a range of environmental pressures. Capturing the social development in birds leading to mate choice, is exceedingly rare and the few experiments that have been conducted on establishing a link between juvenile friendships and later pair formation tend to be of very recent origin [15] but, as will be argued here, deserves our careful attention.

I have looked particularly at birds native to Australia because modern perching/songbirds and parrots first evolved in and speciated in Australia (some lineages surviving the mass extinctions of 65 mya only in East Gondwana, now Australia) $[34,35]$. Such species with extraordinary protracted lineages might eventually offer particularly pertinent insights into the evolution of specific traits. Cooperation within family groups is one of them. In Eurasia and the Americas, species showing cooperative breeding behaviour (i.e., parents having helpers at the nest) rank below $2 \%$, and in some pockets up to $5 \%$, but in Australia cooperative breeding behaviour is known in up to a quarter $22 \%$ of all passerines [36,37].

Some of the longest-lived and biggest-brained (brain weight relative to body weight) birds also live in Australia and these tend to be monogamous and monomorphic living in life-long bonds and small family groups (see Table 1). It will become apparent that in such species it may be particularly likely to establish the possible roots of prosocial behaviour. Since they are extant today, the social organisation and social dynamics across species is partly, at least, accessible and raises questions whether it is appropriate to call one of their traits 'prosocial' and whether this plays any significant role in the dynamics of their life-histories. We will need much further research for confirmation but it is proposed here that very different orders of vertebrates have evolved and arrived at similar aspects of development as have humans. The point that Marshall-Pescini, et al. had made, namely to use follow up studies to see whether the most sharing individual donors and recipients eventually become pairs [23] is particularly pertinent here because a) It is observable behaviour and b) It would suggest that a juvenile stage of development in birds, including the development of prosocial behaviour, may have a direct impact on mate-choice and possibly on long-term survival and reproductive success.

This is also difficult work to do and demands longitudinal studies over long periods of time because species with the social dynamics of interest also take a long time to become socially independent and sexually mature. In bowerbirds and some cockatoo species sexual maturity is not reached before the age of 5-7 years of age (Table 1). In songbirds, such as Australian magpies (Gymnorhina tibicen), sexual maturity is reached in the $2^{\text {nd }}$ year but actual partner choice and reproduction may take five years [38]. White-winged choughs reach sexual maturity only after 4 or 5 years [39]. The point here is that prosocial behaviour is most likely to emerge in long-living species and in these species it may have clear stages of development leading to affiliative behaviour since in these species there is time and opportunity, particularly for social interaction (more of this later). Importantly, if early affiliations or bonding well before sexual maturity and reproduction lead to permanent bond formation later, particularly in monomorphic species with life long bonds, we have to 
ask on what criteria the individuals may base their choice for partner selection?

This paper focuses on what might be termed pre-reproductive prosociality in birds. As has been known for some time but, oddly, has often been ignored, some avian species actually have a 'childhood' and'adolescence'. Much more research is needed on these developmental stages to discover precisely what these stages are species by species, of course, but there is now an emerging body of evidence that strongly suggests that this developmental phase in some avian species may evolve in ways similar to that in humans.

\section{Life Stages and Social Exposure}

For a working definition in this paper, the immediate post-fledging period consists of the weeks or months in which a fledgling is closely supervised by its parents, still fed by the parents and gradually introduced to self-feeding (Table 1) depending on species, and is thus very much parent-focused. Broadly, there are substantial differences in this stage of development between northern and southern hemisphere birds, as Russel and colleagues have identified [40]. They compared length of parental care post-fledging in 126 species of the northern hemisphere $(\mathrm{NH})$ versus 220 species of the southern hemisphere (SH) Australian based (Figure 1) and found that the majority of SH birds - over $60 \%$ - received more than 50 days post-fledging care by parents (compared to just $18 \%$ in $\mathrm{NH}$ species) and, in some species, this care ac- tually extends to well beyond 4 months. A sizeable number of $\mathrm{NH}$ species (over $40 \%$ ), by contrast, have less than 3 weeks post-fledging parental support.

Species without significant post-fledging care tend to become independent very quickly and are not included in further discussions here. Included are species with known long periods of staying in the parental group or territory. Iwaniuk and Nelson [41] found significant differences in as many as eighteen orders of birds showing that length of parental care was strongly correlated with brain size and, as Chiappa, et al. [42] importantly suggested, the length of the altricial period is associated with evolutionary changes in the cognitive system.

Table 1 above provides a few examples of species of particular relevance here because, in their cases, sexual maturity is significantly delayed [40]. For those species in particular, it might even be necessary to subdivide their development into several further stages. How many stages there might be that are sufficiently distinct (for instance in brain development or in social and cognitive skills) to warrant such subdivisions, by and large, has not been fully appraised and will require a good deal more research.

As far as can be ascertained from current knowledge, some avian species may have several clearly defined post-fledging juvenile stages. The first is parent-dependent post-fledging stage which is followed by a juvenile stage proper in which the bird is self-feeding and begins to look more to peers than

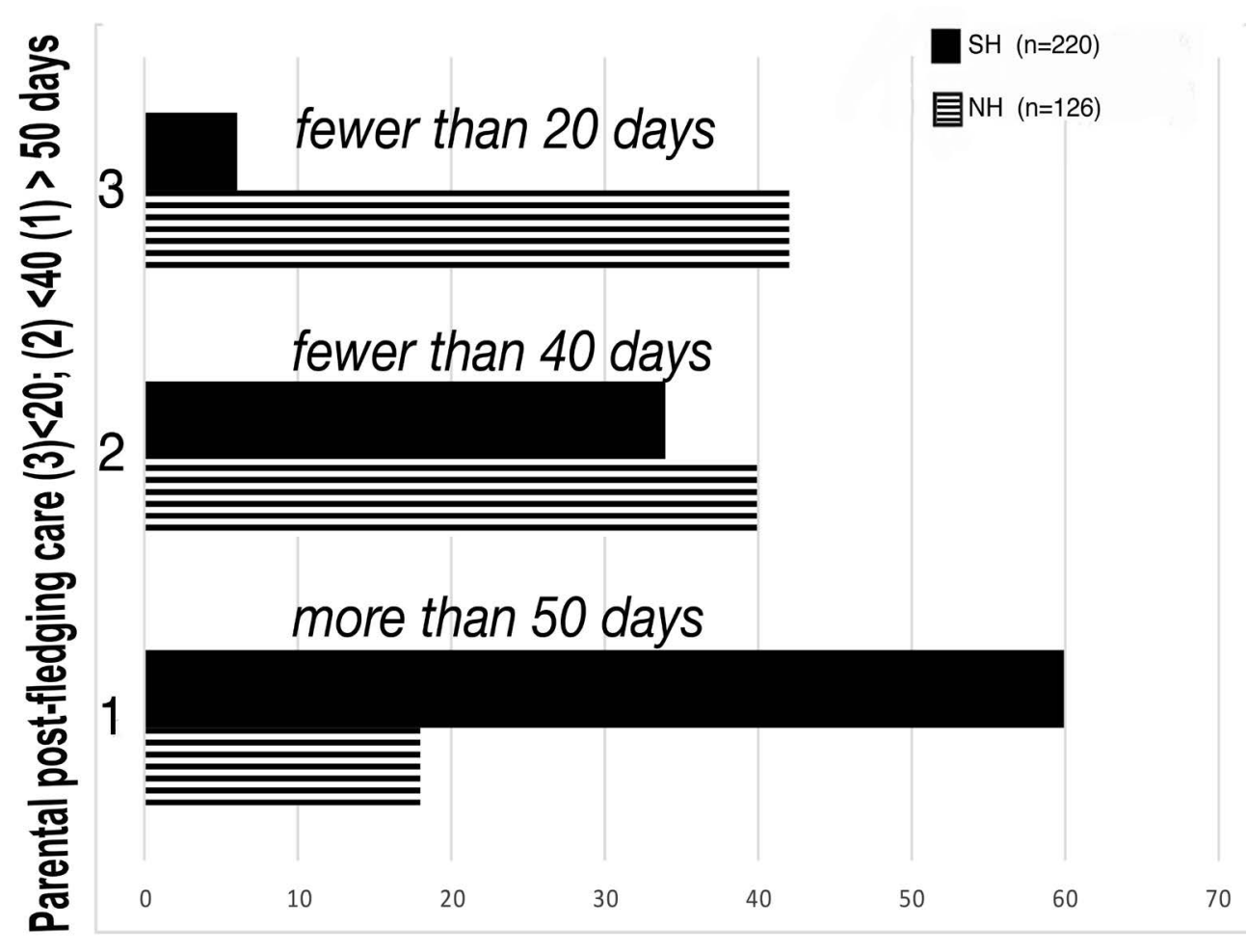

\section{Percentage of species}

Figure 1: Length of parental care in birds.

Black: In southern hemisphere species $-\mathrm{N}=220$ (Australia), Striped: In northern hemisphere species (Europe/USA) $N=126-$ (Adapted from [40]). 
Citation: Kaplan G (2020) Long-Term Attachments and Complex Cognition in Birds and Humans are Linked to Pre-Reproductive Prosociality and Cooperation. Constructing a Hypothesis. Ann Cogn Sci 4(1):127-142

to parents but is still protected and guided by the parents. A third and probably final stage may best be called sub-adulthood in which peer groups form but breeding does not yet occur nor, in many cases, has sexual maturity been reached. In some corvids, bowerbirds, albatrosses and some other seabirds, and particularly in cockatoos, this last, pre-reproductive sub-adult stage seems crucial in the acquisition of social and cognitive skills (Table 1 ) $[43,44]$.

The years spent in a juvenile/pre-sexual/pre-reproductive stage are listed, as are the post-fledging months of parental care. Even in those species that might breed immediately following sexual maturity, usually only a minority will do so. For instance, in Eurasian magpies up to $60 \%$ may not breed immediately once they have reached sexual maturity. These non-breeding birds often form flocks and may even pair up within the flock but not breed. In Australian magpies, despite reaching sexual maturity after the first moult, most breeding attempts are not made before the fifth year $[43,44]$.

With reference to the social model they had studied in the common raven (Corvus corax). Boucherie, et al. has argued that affiliative relationships in ravens may go beyond reproductive partners and extend to kin and "friends" in the non-breeding period [45]. Turned the other way around, it is possible to argue that the social skills needed in the monogamous mating system of many bird species are acquired in immatures and often over a long period of time. Boucherie and colleagues distinguished only three stages in the life history of common ravens (their ancestry is of course Australo/ Papuan): A family stage (birth to fledging) spent with parents and siblings, a second stage (non-breeding) consisting of non-breeding peers of sexually matures and immatures, of related and non-related individuals and, in ravens, that second stage can last for many years; and a third and final stage, the territorial breeding stage with a breeding partner and offspring [45].

The proposal here is that there are not just three life-stages but possible three transitory stages within the juvenile period alone. This concept of 3 juvenile stages could be usefully applied to quite a large group of birds to which this paper is referring. Most of Australia's parrots and cockatoos and many of its songbirds follow the same life-patterns as do common ravens, noting particularly that this second, juvenile, phase is very extended and typically overseen by a long-bonding pair and enriched, or made more complex, by the presence of other juveniles that somehow have to coexist for many years before they can go their own way.

This second life stage is thus a very significant portion of the life of many birds living in close social contexts, ranging from less than one year to, in extreme cases, ten years. It is significant not only in terms of the length of time spent in the juvenile pre-reproductive stage, largely as a time for learning, but also, and importantly, in the social opportunities it affords.

We find a juvenile life stage, similar to that described in ravens, present also in sulphur-crested cockatoos and many other cockatoos and keas (incidentally, at least one of these species have a higher brain/body weight ratio than do ravens
[34]). As Table 1 above shows, sulphur-crested cockatoos tend to reach sexual maturity around 7 years of age and may or may not breed for another 4-5 years. They also live much longer than ravens (between 50-100 years, depending on species). Hence, monogamy is also a significant life event and so is extended juvenile life stage that may well fall into three periods: Post-fledging, juvenile, sub-adult. The first stage indicates parental support for feeding; the second stage: Independent feeding but parental protection, the third stage: Increasing independence and decision making juveniles as said before. Even territorial species, such as Australian magpies (Gymnorhina tibicen) [46], or the Florida scrub-jay (Aphelocoma coerulescens) [47] may qualify for significant juvenile or subadult social experiences (as in playing with other siblings) and then even post dispersal as sub-adults which, in some of these species, often happens to be in the neighbourhood of the natal territory and/or in juvenile flocks [48].

Prosocial behaviour may largely develop in this significant second life stage and be confirmed and social skills generally expanded during sub-adulthood. As in humans, the experiences in these two phases (there may just be one: Juvenile and sub-adult merged of faster developing species) could conceivably profoundly affect the future and likelihood of finding and keeping a partner and even territory. It therefore seems important to argue that this entire juvenile period deserves close attention and detailed study. Yet, apart from research on ravens, this still remains an entirely unstudied area. At least barnacle geese, Branta leucopsis, breeding in the Arctic Circle, preferentially paired up with partners they had known as young birds from previous seasons [49].

In most of the avian species that need a long time before becoming sexually mature and before being ready to breed fall into the category of birds that, with some exceptions, tend to be socially monogamous and are generally noticeably monomorphic. If males and females look entirely or nearly the same, as is the case in many Australian landbirds, the question is how they make a choice for a life partner. Hence, one may need to ask what kind of preparation they might need in order to make a decision of such momentous importance and that answer, I believe, lies in studying the developmental stages in which general social behaviour is forged and shaped [50] (Figure 2).

In view of some of the evidence at hand so far, it seems justified to formulate the hypothesis that mate choice in longterm bonds may be preceded by and anchored in premature coalitions based on mutual choice. One could even call it a pre-sexual prosociality hypothesis suggesting that those pairs with a juvenile history of bonding will also be more likely to mate, be successful in parenting and in producing surviving offspring.

We classify cockatoos as pair bonding birds but it is important to recognise the juvenile stage as a significant developmental stage, made all the more significant if opportunities exist for the juveniles to interact with others of the same developmental stage. The effects of such substantial time spent in a familiar group have probably been underestimated, if they have been considered at all. 


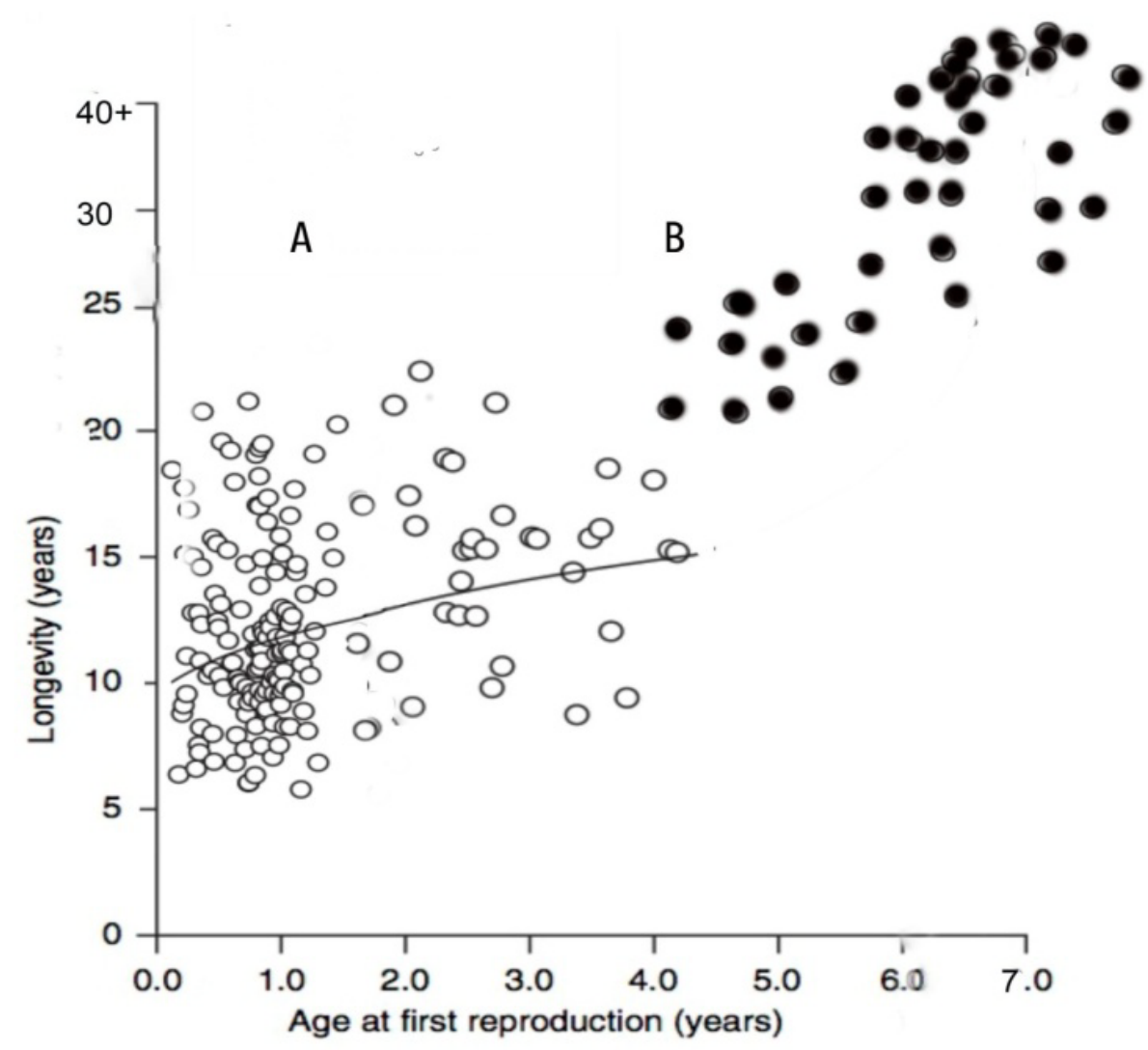

Figure 2: Age at first reproduction versus life expectancy. Note the original figure by Møller, et al. [50] is marked A (clear circles) and $B$ (black circles) show additions of species that reach sexual maturity only after 3-7/8 years, such as cockatoos, ravens and some songbirds. While the correlation between age at first reproduction and longevity appears weak in $A$, once $B$ is added, the correlation between late onset of breeding and longevity emerges quite clearly (more species would need to be added to calculate accurately the line of best fit -hence not added here).

Given the vast number of research papers on mate-choice in birds, it is surprising that this question of the basis of mate choice in this group of birds is asked relatively rarely. It would appear from very recent publications [51] that mate-choice in these species is predicated on mechanisms and choices that are a) More complex than choices based on plumage or song alone; b) Requires an emotional and cognitive framework making alternative choices even conceivable and c) May take a long time to develop.

The next two sections will delineate the concept of prosocial behaviour and bonding against the context of common relevant terms that are often regarded as indicative of key social elements in the literature for successful pairing in birds. In the final section the experiments showing bonding in pre-sexual pre-reproductive birds will be linked to those terms.

\section{Criteria for Friendship and Mate-Choice}

It is not difficult to speculate that bonding between individual birds may hinge on a number of criteria, few of which have as yet been fully investigated. So far, three explanatory terms stand out: Familiarity, similarities and personalities; the latter may relate to past experience (i.e. a new friend displays characteristics of a parent and is therefore instantly 'familiar'). Familiarity has been shown to play an important role in the life of birds, be this familiarity with terrain
[52], with neighbours $[53,54]$ or friends. Indeed, whatever the parameters of the study were, there are clear benefits of familiarity for birds since familiarity with others, terrain, or situations has been shown to reduce risk and stress [55], leading to greater breeding success and even better cognitive performance [56]. Remarkably, one study found that familiarity with competitors led to greater tolerance towards those opponents [57]. It may also be noted that in a case of easing acrimonious contacts with an opponent would also fit into an unusual but apt description of prosociality.

Familiarity may certainly be a strong motivator also in mate choice and it is not clear whether some choices that have been studied and described rest largely on mere familiarity, on personality, a combination of both or on criteria built on acts of prosocial behaviour. In any case, the choices are deliberate and have been found to be successful, at least in reproduction [57].

For example, a longitudinal study of blue-footed boobies (Sula nebouxii), a monogamous long-bonding species, showed that couples that had freely chosen each other and had remained together for some time had greater breeding success (hatching more eggs and producing more fledglings) than newly coupled birds [58]. By contrast, experimentally forced pairs, as the classic research by Yamamoto and colleagues [59] showed in cockatiels (Nymphicus hollandicus), 
Citation: Kaplan G (2020) Long-Term Attachments and Complex Cognition in Birds and Humans are Linked to Pre-Reproductive Prosociality and Cooperation. Constructing a Hypothesis. Ann Cogn Sci 4(1):127-142

were significantly less likely to lay eggs, incubate, or even be fertile than were pairs that had formed naturally. These research results were later confirmed by Spoon and colleagues [60], with the added emphasis on behavioural compatibility which led to personality assessments very much along the same lines as personality assessments devised for dogs and horses, reviewed by [61].

But perhaps personality alone does not capture all aspects of mate choice in long-bonding songbirds and parrots that are not sexually dimorphic. Free choice and preferences do not answer the question on what criteria their choice (and often mutual choice [62]) was initially based. These studies tell us only that birds make actual choices and have preferences, and that is important in itself. Studies addressing other more complex psychological and social issues are of very recent date and the painstaking research has just begun to reveal exceptional subtleties and complexities in mate-choice [63].

One element of mate-choice that is well established in human psychology is referred to as assortative mating, meaning that people of similar abilities form more lasting bonds. And such similar abilities include intelligence at the very top of the list $[64,65]$. Since there is no experimental evidence so far that overall cognitive abilities vary markedly between individual birds, this may in itself not be a testable and useful criterion although similar skill levels may be.

Recent prosocial studies in birds have relied on species with particularly large brains and often with socially monogamous tendencies. Indeed, large brains in birds, relative to body weight, have generally been linked to 'social complexity' and 'social cognition'. As Boucherie, et al. point out [45], these terms are based on the assumption that complex social life is cognitively challenging, and thus can drive cognitive evolution. Mounting evidence from studies on primates and birds suggests that there is indeed a strong correlation between brain size and social complexity and cognition [66-71] (Table 1). Importantly, the rules of complex social life need to be learned and longer periods of supervised parental care may lead to better survival chances $[72,73]$.

Only in the last decades has it been conceivable to probe birds for their affective behaviour and to investigate areas of behaviour that may have affective and cognitive dimensions. The starting point, as often seen in research on human psychology, has been social mimicry, often referred to in the literature as prosocial behaviour [3].

Studies in neuroscience have talked about a social behaviour network within the basal forebrain and midbrain that is common to all vertebrates from teleosts to birds and mammals and a mesolimbic reward system that forms a larger social decision-making network $[74,75]$. At the very least one can say that the ability for adaptive social behaviour and possibly for voluntary decision making [76] towards others of the same species is foregrounded by these ancient and well-preserved networks. Such networks have been shown to be activated in both involuntary and voluntary behaviours. Contagion, for instance, is spontaneous, not learned, and arises readily in social situations amongst people and has been described in detail in the literature for both humans and birds [77-79].

One chief quality, confirmed in humans and among primates more generally, is the ability to form ties with conspecifics, expressed in a number of ways. Synchronising behaviour is one of the oldest conserved behaviours for survival and methods of coordinating reproduction, be this in spawning, fishes swimming in shoals or ungulates moving together in herds (for a review see [80]). Synchronizing activities, over evolutionary time, come to mean much more than simple motor activity of running, or swimming, at least in some species. Mariette and Griffith [81] conducted a detailed study of zebra finch pairs in the wild, demonstrating their affiliative bond by synchronising foraging time, time of arrival and time spent near the nest. And in a study of galah pairs, an extensive repertoire of synchronising movements has been identified, be this simultaneous parallel head-bobbing, simultaneous preening or, interestingly, mirror-image stretching of one wing when facing each other, i.e. one bird stretched the right wing and the other the left wing so that, to the onlooker, the wings of both birds seen together looked like a shield [82]. Most cockatoo pairs express a range of affiliative gestures, such as closely leaning into each other and pseudo-or symbolic allopreening, with heads angled towards each other, or whole-body cuddling next to each other. There is now general agreement, after years of research, that synchrony or joint action promotes cooperative abilities [83] and this seems to hold true of birds as well as humans.

Synchrony of joint action can also be associated with cooperative behaviour. In a clever set of experiments measuring parent's and child's prefrontal neural activity concurrently with functional near-infrared spectroscopy hyperscanning, Reindl, et al. [84] found that only in cooperative social contexts did parent-child dyads show an increased brain-to-brain synchrony in pre-frontal brain areas, the dorsolateral prefrontal cortex) and FPC (frontopolar cortex) [84]. Importantly, synchronicity is also related to specific actions of oxytocins [85] and activity of the medial frontal cortex, easily inviting speculation of links between emotions and social cognition [86]. At the very least, synchrony can be tested because it is interactional and observable [87] but awaits further research in birds.

Adriaense and colleagues [88] have recently tried to organise these related concepts (ranging from pro-social behaviour to empathy), into some manageable order based on Yamamoto's delineation of primate empathy [89]. According to their subdivision there are three possible main areas of relating to conspecifics as presented in a diagram. It is a figure of three interlocking circles, the first (and simplest) is "Matching with others", in which they include synchrony, mimicry and emotional contagion, all forms of aligning behaviour to that of another that may be largely unselfconscious and in itself is not yet an expression of prosociality but it can certainly be a step in that direction and may well be part of a precondition for its emergence. As Hove and Risen [90] have shown, interpersonal synchrony increases affiliation and increases cooperative behaviour [91]. 
Citation: Kaplan G (2020) Long-Term Attachments and Complex Cognition in Birds and Humans are Linked to Pre-Reproductive Prosociality and Cooperation. Constructing a Hypothesis. Ann Cogn Sci 4(1):127-142

\section{Cooperation as a Basis for Attachment}

There is another element in the puzzle of prosocial behaviour and social bonding and this is cooperation. 'Being cooperative', in ornithological circles, refers to species that allow and need helpers at the nest. This in itself is of substantial interest and has been researched in great detail [92]. As said before, Australia has been called the hotspot for cooperative avian species in the world, with a higher concentration of helpers at the nest than anywhere else $[37,93]$.

The term 'cooperation' may also be used in a wider social context, however, and can signal a consistent form of prosocial behaviour which may be adaptive. Cooperation, more broadly, refers to any behaviour that is supportive of any individual in an entire family group and possibly wider social contexts even at times when no offspring are being raised. For instance, galahs raise their offspring in pairs but usually do so in proximity to several other pairs and when the adults need to feed, they utilise a creche system which involves leaving one or two adults in charge of already fledged and adolescent offspring from a number of parents [94]. Similar multi-family group arrangements are known in most cockatoos, many parrot species and songbirds (Table 1), and best studied so far are ravens and some other corvids, babblers [95], whitewinged choughs [40] and apostlebirds [96]. Multifamily-group arrangements have also been observed in noisy miners, bluefaced honeyeaters and starlings and such arrangements are clearly conducive to developing a social framework that is both cognisant of others as 'significant others' and thus of a "self-other orientedness".

Cooperative behaviour may be adaptive in close-knit groups such as apostlebirds but for individual attachments and pair-bonding, it may become an important individual choice. Griffith is right in suggesting that one has to look for the things that make long-term bonds work [97]. There is plenty of anecdotal evidence to support the notion that 'mutual protection and support' can be observed in bonded pairs from the smallest to the largest species. Even in the stratified but cooperatively breeding purple-crowned fairy-wren, Malurus coronatus, subordinate birds form equally strong social bonds with kin as they do with potential mates [98,99].

The question is how far cooperation may stretch. It may be visible in coalition formations, in protection and comforting others, even 'babysitting' as is the case in galah groups (i.e. showing prosocial behaviour). Would helping include recognising someone else's emotional state that is then acted upon, or recognise a problem that one individual cannot solve alone? We have plenty of evidence of this occurring in elephant groups [100] and one instant in common ravens of consoling a defeated partner [146]. It is possible to test some of the dynamics involved in problem-solving task and this has so far been experimentally tested in just a few avian species. These are the familiar number of species already known to be capable of cognitively difficult problem-solving tasks, such as common ravens, Corvus corax [21], African grey parrots, Psittacus erithacus [101], and New Caledonian crows, Corvus moneduloides [102]. Cleverly, in order to solve a problem, it required two partners to solve it, such as moving a platter with food on two separate strings, too far apart to be pulled in by one bird alone and the question was first whether both birds quickly understood that they had to collaborate and then, as an additional hurdle, one bird had to wait for another. In some of these experiments birds were unwilling to wait for a chosen partner to complete the task but there are perhaps some ambiguities as to the motivation of the test subjects and context of the studies. When keas were tested, however, results put keas on par with chimpanzees and elephants in collaborative problem-solving [103]. Interestingly, keas in particular were identified as being better in successfully performing collaborative tasks when they shared the task with individuals that were close affiliates [104]. However, Torres-Ortiz, et al. [105] tested whether cooperative acts such as bringing a food platform within reach of test birds could be achieved regardless of prior affinity with to bird selected to be the experimental partner in the test, here peach-fronted conures, Eupsittula aurea. Their results showed that these conures were well coordinated in pulling the string and patient enough to wait for a partner's arrival before attempting to bring the food closer [105]. It is not clear from the latter experiment whether prosocial behaviour and cooperation on a wide scale of helping and supportive behaviour had become adaptive and required no further learning or social shaping.

Self-other resonance is perhaps also the first step towards theory of mind, i.e. the ability to attribute mental states of intents, desires, emotions, or knowledge to oneself and to others. Some studies have now started to untangle 'desires' in another way, namely as a step for food sharing in Eurasian jays $[28,106]$. Indeed, the ability to indicate "I want something" and the partner/friend/associate being able to identify and respond to this request requires some degree of awareness [106]. In many avian species, one giving to the other is already an adaptation and can be readily observed in courtship rituals (gift giving) or a courting male feeding a female which has usually been interpreted as a signal that the gift giver (usually the male) will be a good provider. However, when such behaviour is taken out of the context of immediate reproduction it may perhaps signify something else. These are the instances for which we have few, if any, answers yet.

There is yet another category of spontaneous cooperation and this, so far, has been thought to apply exclusively to humans. It is based on love and attachment of a bonded pair or a mother and child. Numan and Young [107] compared the details of the neural mechanisms that promote mother-infant bonding in rats and sheep with those that underpin pair bond formation in the monogamous prairie vole, Microtus ochrogaster. They first analysed the neural circuits of the rat's mother-infant interaction in terms of activation of certain circuits and the actions of dopamine and oxytocin and then compared these results with activation in monogamous prairie vole bonded partners. They found some remarkable similarities between the neural mechanisms underlying these two types of bond formations arguing that some well-preserved mechanisms allow stimuli to persistently activate circuits that lead to and maintain enduring social attractions as well as mother-infant bonding in mammals.

According to the theory of attachment in human psychol- 
Citation: Kaplan G (2020) Long-Term Attachments and Complex Cognition in Birds and Humans are Linked to Pre-Reproductive Prosociality and Cooperation. Constructing a Hypothesis. Ann Cogn Sci 4(1):127-142

ogy and neuroscience, individuals develop mental representations of their relations with parents and peers. During the initial stages of romantic attachment, in humans at least, oxytocin increases. The data so far also show that in 'new love' particularly, the dopamine system is involved, and that system also modulates anxiety and pain [108]. By contrast, long-term romantic love recruits opioid-and serotonin-rich neural regions not found in 'new love'. Specifically, oxytocin has been shown to play a critical role in the regulation of pair-bond formation in monogamous mammals, such as in prairie voles [109]. In humans, administration of oxytocin was found to increase bonding-related behaviour, socially reinforced learning and emotional empathy [110], as well as social cognition [111]. It also plays a role in reciprocal parent-infant interactions in both mothers and fathers [112] as well as cooperative situations [113]. Duque and colleagues [114] wanted to know whether oxytocin, known to be an important hormonal mechanism with a positive influence on prosociality in humans and mammals, has similar effects in birds. They tested prosociality in pinyon jays (Gymnorhinus cyanocephalus), already a highly social corvid species that at times spontaneously shares food with others [114], and injected an experimental group with the avian homologue of oxytocin (mesotocin). They demonstrated that, in this species at least, under the influence of high doses of this neuropeptide prosociality increased (by $31.6 \%$ ), as it does in humans.

For instance, in an innovative design, Pan and colleagues [115] linked cooperation with levels of attachment in humans and positive experiences. Their study investigated interactive exchange in lovers and the associated interpersonal brain synchronization (IBS) using functional near-infrared spectroscopy (fNIRS)-based hyper-scanning. They chose three types of social groups: Female-male dyads, lovers, friends, and strangers, and made them perform a cooperative task while brain activity was recorded in right frontoparietal regions. Their experiments yielded very clear results that lovers displayed better cooperative behaviour compared to friend and stranger dyads and this was matched in lover dyads by increased IBS in the right superior frontal cortex, and it also covaried with their task performance. The lovers' coordinated response time was also shorter than in any of the other tested dyads. Ultimately, then, in the right conditions prosocial behaviour is not just a pleasant experience for the recipient but seems to facilitate positive mood changes also in the giver.

We do not have studies in birds that show coordination in terms of brain synchronisation. We do have evidence in birds of strong partner coordination, however. For instance, evidence of joint actions may be in the form of duets between bonded pairs, in joint predator mobbing by a pair or group and these coordinated activities are well documented $[116,117]$. Hall and Magrath [118] found that pairs of magpie-larks are more likely to sing better-coordinated duets when well established, while those of newly mated birds tend to overlap. Excellent temporal precision of duets prompted other researchers to conclude that the temporal precision of a duet could reveal to others that the duetting pair is an experienced team and thus attest to the quality of their coalition and their ability to cooperate which in turn could make the pair more intimidating to a potential intruder [119].

Somewhat different but also easy to test in the field are exemplifications of coordination when a family group jointly mobs an invading predator. The best coordinated mobbing activities are also those that save a territory from intrusion by competing conspecifics or by predators. This has also been well documented and has been written about for at least the last hundred years [120].

While most coordinated mobbing events are defensive (vocal or visual) it generally holds true that cooperating individuals have a greater chance to drive the predator from the neighbourhood than those that are not cooperating, as already Konrad Lorenz noted in 1931 [121]. Proactive mobbing attacks by pairs and family groups on birds of prey are less common but in those documented cases, as in Australian magpies, precision of coordination is particularly evident and highly successful [122].

Not all of these examples by themselves indicate that close cooperation means deep attachment, although it can reflect this. By itself, not everyone would call this a 'prosocial' behaviour. However, if one individual warns another of impending danger and then proceeds to help and fly to the scene of turmoil or high risk certainly suggests the kind of behaviour one would not hesitate to call prosocial or even affiliative.

\section{Compatibility and Early Bond Formation}

The findings on human mate choice, as described earlier, have shown that prosocial behaviour is likely to be stronger and more readily expressed towards someone who is similar to the individual called upon to help [123]. To individuals to whom we attribute qualities similar to our own, a more spontaneous chance of active supportive intervention and participation has been confirmed in countless studies on human adolescence [124].

Compatibility in birds is now widely acknowledged as a very important precondition for reproductive success overall [125]. Compatible zebra finch pairs, for instance, were shown to have a 37 per cent lower rate of offspring mortality [126] and, as was shown in great tits Parus major, compatible pairs stayed together [127]; i.e. pairs that are well matched according to personality trait indices have overall greater reproductive success [125]. Mismatched pairs, as was shown in Gouldian finches Erythrura gouldiae, maintained elevated stress hormone levels over several weeks, which also delayed egg laying [128]. Recent data from Steller's jays, Cyanocitta stelleri, a corvid that lives largely in the Rocky Mountains, has revealed that shared traits of exploratory and risk-taking behaviour make partners more compatible than others in several ways: They nest earlier and have better fledging rates than pairs scoring lower in similarity of such traits [129]. It may also contribute to the longevity of the pair bond. Compatibility in birds usually means having very similar attributes be they personality or hormonally-based similarities which have been shown to have many benefits, including stability of the bond [130] as already discussed above in some detail. Clearly, there is now evidence across a wide range of species across 
Citation: Kaplan G (2020) Long-Term Attachments and Complex Cognition in Birds and Humans are Linked to Pre-Reproductive Prosociality and Cooperation. Constructing a Hypothesis. Ann Cogn Sci 4(1):127-142

the world that compatibility is an important criterion for the maintenance of a bond.

However, similarities in personality traits are not always a good explanation. As was discussed before, there is plenty of evidence now that birds use synchronising techniques particularly in those that are long-bonding, synchronising behaviour is also often part of a ceremonious acknowledgement of the intention to pair up. Such ceremonies may include walking together, preening, or even dancing in a coordinated fashion. In some animals, such ceremonies are necessary to induce ovulation in the female and get both partners into a reproductive state [131]. In highly evolved monogamous avian species, rituals may indicate the intention to form a pair, reinforce bonds and/or even resolve conflicts [132].

The question is why synchronising is needed if the individuals are already very similar in appearance, personality or cognitive ability and/or skills? Clearly, learning to synchronise activities and behaviour generally is a dynamic process in which two individuals that may be quite different one from another are willing to learn or have learned to synchronise their behaviour and actions in very specific situations and contexts. Theoretically, this would appear to be quite important.

Familiarity, as distinct from similarity, has an immediately apparent advantage. It is the least stressful way of relating to another even without additional stresses of breeding and raising offspring. Note that the association between pairs-tobe is not directly linked to sex and reproduction.

In-groups or subgroups of the kind that most cockatoos form, including friendships and close alliances and even pair formations, may begin in the second or third year post-fledging (own observ.). Such pre-mature pairs are easily identified because they roost together and are seen sitting very closely next to each other (as can be seen in Figure 3). Adult pairs can be identified by sitting apart from the group and flying together in exploratory flights for food and water.

A study by Teitelbaum, et al. [133], one of the first of its kind to my knowledge, that has addressed the issues raised here has provided a scientific basis for the hypothesis presented in this paper. The researchers undertook a systematic investigation of pre-breeding association patterns of longterm monogamous pairs and examined entire life histories based on tracking data of migratory whooping cranes, Grus americana, a species that had been critically endangered and is slowly recovering due to concerted breeding programs. They had tagged a large number of birds before sexual maturity and then analysed 58 breeding pairs of the ones that had been tagged. They then made the astonishing discovery that more than sixty per cent of the 58 breeding pairs had started associating at least twelve months before first breeding, while 27 breeding pairs (sixteen per cent) had started associating

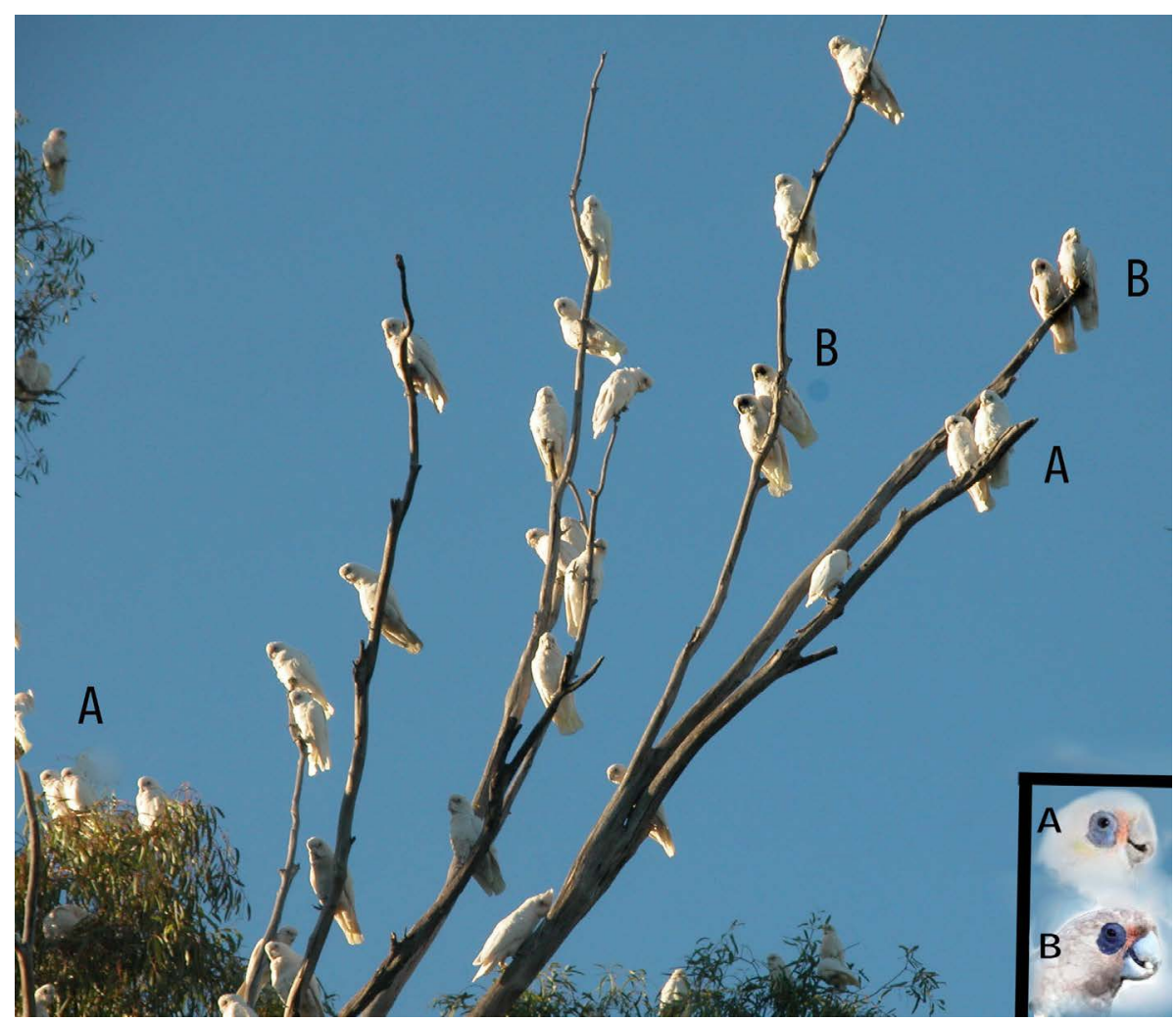

Figure 3: A group of 36 little corellas (Cacatua sanguinea) are seen in this image roosting together. The pairs marked A are adult pairs, all others are juveniles. Note that those marked B are juveniles/pairs/friends roosting together. They may do so for years before they decide to confirm the bond and then reproduce.

Insert A- adult, Insert B: Juvenile. Juveniles are usually recognisable in the field (with binoculars) by their slightly darker blue eye patches and more scruffy and darker area across the nares and head. (Image: Gisela Kaplan). 
Citation: Kaplan G (2020) Long-Term Attachments and Complex Cognition in Birds and Humans are Linked to Pre-Reproductive Prosociality and Cooperation. Constructing a Hypothesis. Ann Cogn Sci 4(1):127-142

with their future partner over two years before first breeding. These associations happened before either one of the future partners had reached sexual maturity. The researchers suggested that there are potential benefits for pre-breeding relationships by providing support in competitive contexts and increasing partner familiarity. In other words, the association between pairs-to-be is not directly linked to sex and reproduction and this turns current assumptions about the compulsion to breed on its head.

To test species with certain characteristics and to be mindful of exact age groups within the juvenile stages, de Kort, et al. [24] explored the food sharing in jackdaws (Corvus monedula) and found that the older juveniles tended to share more food than younger birds. Von Bayern, et al. [25] found in their study, also of juvenile jackdaws, generous giving and sharing behaviour and suggested as a functional explanation that such behaviour might foster the formation of social bonds. Horn and colleagues [14] chose a cooperatively breeding corvid, the azure-winged magpie (Cyanopica cyana) and showed that the birds required no cues and no long hours in training because the behaviour is already a part of their social repertoire [14]. Many parrots are now also known to voluntarily share food resources [19].

Again, such results need to be read in conjunction with very careful considerations of the type, length and outcome of socialising during their juvenile period. So far, for most of parrot and cockatoo species there has been no follow up, as to whether the parrots that share with one another are also later found to form pairs, were in fact "childhood sweethearts" (Figure 3) and later form a permanent bond. Studies of this kind are very difficult to do, of course, either because of the length of time needed to conduct such longitudinal studies and because many parrot species appear monomorphic to us and need to be banded for identification and possibly even be sexed in order to conduct such experiments in the natural environment.

To come back to the review by Marshall-Pescini and colleagues [23]. They had rightly argued if behavioural experiments are conducted in laboratories, the experimenters have to consider carefully what the social arrangements of the species being tested actually are, both in terms of length of juvenile development and in terms of the social contacts, to what end they are developed and also what the particular history of individual associations of birds to be tested have been. Unless such a species is known for long-term pair bonds and some level of cooperation in the broader social group in which individuals were raised, experiments set up to test prosocial trends are likely to fail [134]. When common ravens, Corvus corax, were tested on their prosocial behaviour, Lambert and colleagues [135] found that unpaired (or unbonded?) ravens did not act for the benefit of conspecifics in the absence of immediate self-gain, as has been found also in chimpanzees and other primates [136] unless some self-interest or pre-existing bonds exist [137]. Their relationships are social but negotiated, not necessarily bonded. There is a substantial difference between these two forms of social relationships.

More generally, the way mate choice has been studied in birds generally, has so far largely focussed on the END of a prosocial development, namely at the moment when actual mate-choice has already occurred or at the moment of rituals expressing a mutual intention for long-term bonding or even just in terms of their breeding success. What makes the group of birds referred to in this paper (the monomorphic, socially monogamous, large-brained birds; examples in Table 1), so unusual and so suitable for comparisons with human behaviour and bonding is that mate choice may have taken years in shaping into a workable social, cognitive and affective form.

In species such as jackdaws or the cooperative breeding azure-winged magpie, or in corellas, galahs and sulphur-crested cockatoos, and possibly many other parrots and songbirds, as well as even water and shorebirds, is that the trigger for pair formation may not be sex and it is most likely not mating or plumage patterns or colour or song. Indeed, a pair may have been together for the best part of five years before they are even ready to mate (Figure 2 ).

In other words, as in humans, in some avian species it is not the impetus for reproduction that makes birds pair-bond but pair bonding that makes them reproduce. Given that sequence, pair bonding is the lynchpin for further developments in the life histories and cognition of birds.

This conclusion does not necessarily explain the link between prosocial behaviour and bonding. One would need to speculate here that social bonding might even precede expressions of prosocial behaviour. Whether giving and sharing is an expression of affiliation or an adaptation to intergenerational cultural transmission of cooperative behaviour is not clear and has not been tested. In cooperative species (termed so for having helpers at the nest to feed the next generation) the helpers are usually sons and daughters of the previous year. They are charged with the task of delivering food to offspring and have to give away food to others with whom they cannot possibly have formed any direct affiliation. It is entirely unclear why they help and indeed give food away. Some may occasionally only pretend to do so but the majority of one-year-old helpers actually oblige. Whether or not this is a training ground for prosocial behaviour generally is also not clear but, in this scenario, very common in Australian species, one might even surmise that prosocial behaviour occurs first (and may even be enforced by the parents) and, given this level of cooperation, may lead to a capacity for social bonding.

Finally, and not insignificantly, the link to general cognitive ability should not be underrated. It is not just time that is needed, it is some basic appreciation that other individuals (apart from parents) matter. I like the term "self-other-orientedness" as an alternative to the term 'prosociality' because, certainly in bird studies, it makes the point well that the becoming of orientation towards some other individual is a substantial and, indeed, a very large step in evolution. A significant group of birds, dogs, elephants, primates, some other mammals and humans have achieved this transition but not many other orders and species. It is that step that may be helped along by cognitive capacity. A recent study by Guo, et 
Citation: Kaplan G (2020) Long-Term Attachments and Complex Cognition in Birds and Humans are Linked to Pre-Reproductive Prosociality and Cooperation. Constructing a Hypothesis. Ann Cogn Sci 4(1):127-142

al. [138] highlighted and concluded their study (on humans) by saying that a) "Intelligence is associated with self-reported prosocial behaviour in daily life". And b) Higher intelligence is "contributive to emotional sensitivity and a greater concern for others". Given that the clearest indication of prosocial behaviour in birds so far identified is in species with the largest brains and the longest lifespans might give pause for thought. The surprising analogies, given the evolutionary distance between human and birds, be this in social [139], developmental [140] and even in some important similarities in mechanisms and structures of the brain $[70,141]$, continue to invite further investigation.

\section{Conclusion}

The point of this paper was to highlight that some species of birds have similar social conditions and plenty of time and opportunity, as human adolescents have, to form pre-sexual and pre-reproductive friendships and attachments. Importantly, they also have the brain mechanisms and networks to activate such social bonds. It was argued that long-term bonds may be preceded by and anchored in pre-mature pair bond based on mutual choice. Bonding behaviour can be readily observed even in the wild by watching their roosting (Figure 3) and, if applicable, the preening pattern while prosocial behaviour is far more difficult to observe unless these are acts by helpers at the nest or courtship activities of males providing edible gifts to a potential partner.

The idea of bonding is hardly new in birds. What is new is the process by which it might occur and that it is decoupled from sex and reproduction. Its function is to prepare birds for stable relationships and life-long affiliations that are as successful in birds as in humans.

Because of the latest findings described in this paper, it is proposed that long-term bonds, particularly of monomorphic and socially monogamous species may be preceded by and anchored in this pre-mature pair bond based on mutual choice. This is so far largely a pre-sexual prosociality hypothesis suggesting that those pairs with juvenile history of bonding will also be likely to form bonds early and be more successful in parenting and in producing surviving offspring. Indeed, a pre-sexual bonding may become a training ground for learning mutual responsiveness between the pair partners even including voluntary sharing and mutual support. Interestingly, a recent paper found (in humans) that intelligence is associated with self-reported prosocial behaviour in daily life and contributive to emotional sensitivity and a greater concern for others [142]. It seems that some species (Table 1) and possibly many others that have not yet been studied, show the same link between strong affiliation and cognition.

Hence there is some support for the view that prosocial behaviour is a preparation for social bonding if one views pro-sociality as a self-other resonance, the ability of an organism to connect with another in emotional and significant ways.

While those signs of 'other-directedness' may appear small, this alone is a huge step in evolution. To turn self-centred interests into 'other directedness' and acknowledge another individual as significant --to the point that one will do nice things for the other---is suggestive of a tremendous change in reproductive strategies in birds. Ungulates do not preen each other, but birds do and primates have developed a way of showing support, even affection (or appeasement), by grooming one another, hugging, embracing etc.

As the study by Teitelbaum [133] showed, adolescent bonds may lead directly into pair bonds some years later. Intense social learning and social experiences make adolescence in humans generally a very unstable time because this period subjects the individual adolescent to both pleasures and often substantial pressures and, as one paper found, may also explain prosocial motivation [143]. Adolescence/juvenile stages in birds may begin to look very similar to those of some primates and humans and worthy of our attention.

Obviously, a good deal of research needs to be done and preferably in multidisciplinary frameworks, be this in neuroscience, endocrinology, ethology and comparative psychology to test how many changes actually occur in the three stages post-fledging (fledgling, juvenile, sub-adult) and whether there are elements of convergent evolution with humans. Such work has already begun [143]. Development is a dynamic process, be this in the brain, in hormonal activations, in behaviour, in social contacts and contexts as well as in the environment. Obviously, this is outside and in addition to specific studies on sexual imprinting in juvenile birds in species (such as ducks) of which we have very detailed and comprehensive studies [144].

The now classic paper by Nowicki and colleagues [145] produced a chronological graph, showing the developmental stages of the song system in zebra finches, when and exactly which branches of the song control system had completed their development and which had not connected yet, and on which days. In the same figure, it showed precisely when the birds fledged and how far the brain development, and specifically the song control system, had progressed in building all relevant connections. Such developmental data linked with life stages and internal developmental data help identify clearly some of the dynamic changes in development. We have not reached this stage yet with respect to affective development in birds. In zebra finches, song learning is confined to a sensitive period. It is well possible that, in some species, there could be a sensitive period for learning prosocial behaviour and, if missed or disturbed, can have negative consequences as it has in humans. Knowing this in detail, among many other good reasons, may help our understanding concerning possible evolutionary constraints or processes converging with those known in humans.

Malleability of brain development and behaviour that can ultimately decide whether some birds will ever find and keep a partner, will be successful in it and will have the right social, cognitive and affective tools to successfully raise offspring. All these crucial life events might well be decided during the stages of adolescence. Not all mate choice is driven by competition but, as the limited evidence so far suggests, can be driven by subtle social and affective processes built on a model of cooperation. 
Citation: Kaplan G (2020) Long-Term Attachments and Complex Cognition in Birds and Humans are Linked to Pre-Reproductive Prosociality and Cooperation. Constructing a Hypothesis. Ann Cogn Sci 4(1):127-142

\section{References}

1. Eisenberg N, Mussen PH (1989) The roots of prosocial behavior in children. Cambridge University Press.

2. Cronin KA (2012) Prosocial behaviour in animals: The influence of social relationships, communication and rewards. Animal Behaviour 84: 1085-1093.

3. Stel M, van Baaren RB, Vonk R (2008) Effects of mimicking: Acting prosocially by being emotionally moved. European $J$ of Social Psychology 38: 965-997.

4. Patton GC, Viner R (2007) Pubertal transitions in health. Lancet 369: 1130-1139.

5. Güroglu B, van den Bos W, Eveline A Crone (2014) Sharing and giving across adolescence: An experimental study examining the development of prosocial behaviour. Front Psychol 5: 291.

6. Ferschmann L, Vijayakumar N, Grydeland H, et al. (2019) Prosocial behavior relates to the rate and timing of cortical thinning from adolescence to young adulthood. Dev Cogn Neurosci 40: 100734.

7. Blankenstein NE, Telzer EH, Do KT, et al. (2019) Behavioral and neural pathways supporting the development of prosocial and risk-taking behavior across adolescence. Child Dev 91: e665-e681.

8. Gross J, Emmerling F, Vostroknutov A, et al. (2018) Manipulation of pro-sociality and rule-following with non-invasive brain stimulation. Sci Rep 8: 1827.

9. van den Bos W, Westenberg M, van Dijk E, et al. (2010) Development of trust and reciprocity in adolescence. Cognitive Development 25: 90-102.

10. Christov-Moore L, lacoboni M (2016) Self-other resonance, its control and prosocial inclinations: Brain-behavior relationships. Hum Brain Mapp 37: 1544-1558.

11. Do KT, McCormick EM, Telzer EH (2019) The neural development of prosocial behavior from childhood to adolescence. Soc Cogn Affect Neurosci 14: 129-139.

12. Ferraro FR (2019) Special Issue on Psychology of Prosocial Behavior. Current Psycholology 38.

13. De Waal FBM, Suchak M (2010) Prosocial primates: Selfish and unselfish motivations. Philos Trans R Soc Lond B Biol Sci 365: 2711-2722.

14. Horn L, Scheer C, Bugnyar T, et al. (2016) Proactive prosociality in a cooperatively breeding corvid, the Azure- Winged Magpie (Cyanopica Cyana). Biol Lett 12: 20160649.

15. Dale R, Quervel-Chaumette M, Huber L, et al. (2016) Task differences and prosociality; Investigating pet dogs' prosocial preferences in a token choice paradigm. PLoS One 11: e0167750.

16. Tang TLP, Sutarso T, Davis GMTW, et al. (2008) To help or not to help? The Good Samaritan Effect and the love of money on helping behavior. Journal of Business Ethics 2: 865-887.

17. Feistner AT, McGrew WC (1989) Food-sharing in primates: A critical review. Perspectives in Primate Biology 3: 21-36.

18. Duque JF, Stevens JR (2016) Voluntary food sharing in pinyon jays: The role of reciprocity and dominance. Animal Behaviour 122: 135-144.

19. Brucks D, von Bayern AMP (2020) Parrots voluntarily help each other to obtain food rewards. Curr Biol 30: 292-297.

20. Massen JJM, Lambert M, Schiestl M, et al. (2015) Subadult ravens generally don't transfer valuable tokens to conspecifics when there is nothing to gain for themselves. Front Psychol 6: 885.

21. Rogers LJ, Kaplan G (2003) Spirit of the Wild Dog. Allen \& Unwin, Sydney, 229.

22. Chakrabarti S, Jhala YV (2017) Selfish partners: Resource partitioning in male coalitions of Asiatic lions. Behav Ecol 28: 1532-1539.

23. Marshall-Pescini S, Dale R, Quervel-Chaumette M, et al. (2016) Critical issues in experimental studies of prosociality in nonhuman species. Anim Cogn 19: 679-705.

24. De Kort SR, Emery NJ, Clayton NS (2006) Food sharing in jackdaws, Corvus monedula: What, why and with whom? Animal Behaviour 72: 297-304.

25. von Bayern AMP, de Kort SR, Clayton NS, et al. (2007) The role of food-and object-sharing in the development of social bonds in juvenile jackdaws (Corvus monedula). Behaviour 144: 711-733.

26. Schwab C, Swoboda R, Kotrschal K, et al. (2012) Recipients affect prosocial and altruistic choices in jackdaws, Corvus monedula. PLoS One 7: e34922.

27. Ostojić L, Shaw RC, Cheke LG, et al. (2013) Evidence suggesting that desire-state attribution may govern food sharing in Eurasian jays. Proc Natl Acad Sci USA 110: 4123-4128.

28. Ostojić L, Legg EW, Shaw RC, et al. (2014) Can male Eurasian jays disengage from their own current desire to feed the female what she wants? Biol Lett 10: 20140042.

29. Scheid C, Schmidt J, Noe R (2008) Distinct patterns of food offering and co-feeding in rooks. Animal Behaviour 76: 17011707.

30. Di Lascio F, Nyffeler F, Bshary R, et al. (2013) Ravens (Corvus Corax) are indifferent to the gains of conspecific recipients or human partners in experimental tasks. Anim Cogn 16: 35-43.

31. Massen JJ, Ritter C, Bugnyar T (2015) Tolerance and reward equity predict cooperation in ravens (Corvus corax). Sci Rep 5: 15021.

32. Péron F, John M, Sapowicz S, et al. (2012) A study of sharing and reciprocity in grey parrots (Psittacus erithacus). Animal Cognition 16: 197-210.

33. Olkowicz S, Kocourek M, Lučan RK, et al. (2016) Birds have primate-like numbers of neurons in the forebrain. Proc Natl Acad Sci U S A 113: 7255-7260.

34. Edwards SV, Boles WE (2002) Out of Gondwana: The origin of passerine birds. Trends in Ecology \& Evolution 17: 347-349.

35. White NE, Phillips MJ, Gilbert MTP, et al. (2011) The evolutionary history of cockatoos (Aves: Psittaciformes: Cacatuidae). Molecular Phylogenetics and Evolution 59: 615-622.

36. Boland CRJ, Cockburn A (2002) Short sketches from the long history of cooperative breeding in Australian birds. Emu - Austral Ornithology 102: 9-17.

37. Feeney WE, Medina I, Somveille M, et al. (2013) Brood parasitism and the evolution of cooperative breeding in birds. Science 342 : 1506-1508.

38. Kaplan G (2019) The Australian magpie: Biology and behaviour of an unusual songbird. ( $\left.2^{\text {nd }} e d n\right)$, CSIRO Publishing, Melbourne.

39. Heinsohn R, Dunn P, Legge S, et al. (2000) Coalitions of relatives and reproductive skew in cooperatively breeding white-winged choughs. Proc Biol Sci 267: 243-249. 
Citation: Kaplan G (2020) Long-Term Attachments and Complex Cognition in Birds and Humans are Linked to Pre-Reproductive Prosociality and Cooperation. Constructing a Hypothesis. Ann Cogn Sci 4(1):127-142

40. Russell EM, Yom-Tov Y, Geffen E (2004) Extended parental care and delayed dispersal: Northern, tropical, and southern passerines compared. Behavioral Ecology 15: 831-838.

41. Iwaniuk AN, Nelson JE (2003) Developmental differences are correlated with relative brain size in birds: A comparative analysis. Canadian Journal of Zoology 81: 1913-1928.

42. Chiappa P, Singh S, Pellicer F (2018) The degree of altriciality and performance in a cognitive task show correlated evolution. PloS One 13: e0205128.

43. An age: The animal ageing and longevity database. https:// genomics.senescence.info/species/

44. Brouwer K, Jones ML, King CE, et al. (2000) Longevity records of Psittaciformes in captivity. International Zoo Yearbook 37: 299316.

45. Boucherie PH, Loretto MC, Massen JJ, et al. (2019) What constitutes "social complexity" and "social intelligence" in birds? Lessons from ravens. Behav Ecol Sociobiol 73: 12.

46. Kaplan G (2018) Development of meaningful vocal signals in a juvenile territorial songbird (Gymnorhina Tibicen) and the dilemma of vocal taboos concerning neighbours and strangers. Animals (Basel) 8: 228

47. Tringali A, Sherer DL, Cosgrove J, et al. (2020) Life history stage explains behavior in a social network before and during the early breeding season in a cooperatively breeding bird. Peer J 8: e8302.

48. Baldwin M (2016) Group movements of the white-winged chough. Australian Field Ornithology 4: 69-77.

49. Choudhury S, Black JM (1994) Barnacle geese preferentially pair with familiar associates from early life. Animal Behaviour 48: 8188.

50. Møller AP (2006) Sociality, age at first reproduction and senescence: Comparative analyses of birds. J Evol Biol 19: 682689.

51. Eyck HJ, Crino OL, Kraft FLO, et al. (2020) Birds from matched developmental environments breed faster. Behavioral Ecology and Sociobiology 74.

52. Brown CR, Brown MB, Brazeal KR (2008) Familiarity with breeding habitat improves daily survival in colonial cliff swallows. Anim Behav 76: 1201-1210.

53. Beletsky LD, Orians GH (1989) Familiar neighbors enhance breeding success in birds. Proc Natl Acad Sci USA 86: 7933-7936.

54. Grabowska-Zhang AM, Sheldon BC, Hinde CA (2012) Long-term familiarity promotes joining in neighbour nest defence. Biology Letters 8: 544-546.

55. Raposa EB, Laws HB, Ansell EB (2016) Prosocial behavior mitigates the negative effects of stress in everyday life. Clin Psychol Sci 4: 691-698.

56. Cibulski L, Wascher CA, Weiß BM, et al. (2014) Familiarity with the experimenter influences the performance of common ravens (Corvus corax) and carrion crows (Corvus corone corone) in cognitive tasks. Behavioural processes103: 129-137.

57. Senar JC, Camerino M, Metcalfe NB (1990) Familiarity breeds tolerance: The development of social stability in flocking siskins (Carduelis spinus). Ethology 85: 13-24.

58. Sanchez-Macouzet O, Rodriguez C, Drummond H (2014) Better stay together: Pair bond duration increases individual fitness independent of age-related variation. Proc Biol Sci 281.
59. Yamamoto JT, Shields KM, Millam JR, et al. (1989) Reproductive activity of force-paired cockatiels (Nymphicus hollandicus). The Auk 106: 86-93.

60. Spoon TR, Millam JR, Owings DH (2006) The importance of mate behavioural compatibility in parenting and reproductive success by cockatiels, Nymphicus hollandicus. Animal Behaviour 71: 315326.

61. Wieldraaijer $L$ (2018) An evaluation of the underlying causes of personality-based assortative mating. University of Groningen, Netherlands.

62. Bergstrom CT, Real LA (2000) Toward a theory of mutual mate choice: Lessons from two-sided matching. Evolutionary Ecology Research 2: 493-508.

63. Kaplan G (2019) Bird bonds sex, mate-choice and cognition in Australian native birds. Pan Macmillan, Sydney.

64. Domingue BW, Fletcher J, Conley D, et al. (2014) Genetic and educational assortative mating among US adults. Proc Natl Acad Sci USA 111: 7996-8000.

65. Plomin R, Deary IJ (2015) Genetics and intelligence differences: Five special findings. Mol Psychiatry 20: 98-108.

66. Rogers L, Kaplan G (2004) Comparative vertebrate cognition: Are primates superior to nonprimates? In: Kluwer primatology series. Developments in primatology: Progress and prospect, Kluwer Academic/Plenum Publishers, New York.

67. Kaplan G (2015) Bird minds. Cognition and behaviour of Australian native species. CSIRO Publishing, Melbourne, 286.

68. Güntürkün O, Bugnyar T (2016) Cognition without cortex. Trends Cogn Sci 20: 291-303.

69. Lefebvre L, Reader SM, Sol D (2004) Brains, innovations and evolution in birds and primates. Brain Behav Evol 63: 233-246.

70. Kabadayi C, Osvath M (2017) Ravens parallel great apes in flexible planning for tool-use and bartering. Science 357: 202204.

71. Krasheninnikova A, Berardi R, Lind MA, et al. (2019) Primate cognition test battery in parrots. Behaviour 156: 721-761.

72. Heyes C (2012) What's social about social learning? J Comp Psychol 126: 193-202.

73. Slagsvold T, Wiebe KL (2011) Social learning in birds and its role in shaping a foraging niche. Phil Trans R Soc B 366: 969-977.

74. Goodson JL (2005) The vertebrate social behaviour network: Evolutionary themes and variations. Hormones and Behavior 48: 11-22.

75. O'Connell LA, Hofmann HA (2011) The vertebrate mesolimbic reward system and social behavior network: A comparative synthesis. J Comp Neurol 519: 3599-3639.

76. Laycraft KC (2019) Decision-making as a self-organizing process. Annals of Cognitive Science 3.

77. Osvath M, Sima M (2014) Sub-adult ravens synchronize their play: A case of emotional contagion. Animal Behavior and Cognition 1: 197-205.

78. Schwing R, Nelson XJ, Wein A, et al. (2017) Positive emotional contagion in a New Zealand parrot. Curr Biol 27: 213-214.

79. Norscia I, Palagi E (2011) Yawn contagion and empathy in Homo sapiens. PloS One 6: e28472.

80. Schirmer A, Meck WH, Penney TB (2016) The socio-temporal brain: Connecting people in time. Trends Cogn Sci 20: 760-772. 
Citation: Kaplan G (2020) Long-Term Attachments and Complex Cognition in Birds and Humans are Linked to Pre-Reproductive Prosociality and Cooperation. Constructing a Hypothesis. Ann Cogn Sci 4(1):127-142

81. Mariette MM, Griffith SC (2012) Nest visit synchrony is high and correlates with reproductive success in the wild zebra finch Taeniopy giaguttata. Journal of Avian Biology 43: 131-140.

82. Rogers L, McCulloch H (1981) Pair-bonding in the galah, Cacatua roseicapilla. Bird Behaviour 3: 80-92.

83. Valdesolo P, Ouyang J, De Steno D (2010) The rhythm of joint action: Synchrony promotes cooperative ability. Journal of Experimental Social Psychology 46: 693-695.

84. Reindl V, Gerloff C, Scharke W, et al. (2018) Brain-to-brain synchrony in parent-child dyads and the relationship with emotion regulation revealed by fNIRS-based hyperscanning Neuroimage 178: 493-502.

85. Atzil S, Hendler T, Zagoory-Sharon O, et al. (2012) Synchrony and specificity in the maternal and the paternal brain: Relations to oxytocin and vasopressin. J Am Acad Child Adolesc Psychiatry 51 798-811.

86. Amodio DM, Frith CD (2006) Meeting of minds: The medial frontal cortex and social cognition. Nat Rev Neurosci 7: 268-277.

87. Hoehl S, Fairhurst M, Schirmer A (2020) Interactional synchrony: Signals, mechanisms, and benefits. Social Cognitive and Affective Neuroscience.

88. Adriaense JEC, Koski SE, Huber L, et al. (2020) Challenges in the comparative study of empathy and related phenomena in animals. Neuroscience \& Biobehavioral Reviews 112: 62-82.

89. Yamamoto S (2017) Primate empathy: Three factors and their combinations for empathy-related phenomena. Wiley Interdiscip Rev Cogn Sci 8.

90. Hove MJ, Risen JL (2009) It's all in the timing: Interpersonal synchrony increases affiliation. Social Cognition 27: 949-960.

91. Reddish P, Fischer R, Bulbulia J (2013) Let's dance together: Synchrony, shared intentionality and cooperation. PLoS One 8: e71182.

92. Cockburn A (2006) Prevalence of different modes of parental care in birds. Proc Biol Sci 273: 1375-1383.

93. Heinsohn RG, Double MC (2004) Cooperate or speciate: New theory for the distribution of passerine birds. Trends Ecol Evol 19: 55-57.

94. Rowley I (1980) Parent-offspring recognition in a cockatoo, the Galah, Cacatua Roseicapilla. Australian Journal of Zoology 28: 445-456.

95. Sorato E, Griffith SC, Russell AF (2016) The price of associating with breeders in the cooperatively breeding chestnut-crowned babbler: Foraging constraints, survival and sociality. J Anim Ecol 85: 1340-1351.

96. Woxvold IA, Magrath MJ (2005) Helping enhances multiple components of reproductive success in the cooperatively breeding apostlebird. Journal of Animal Ecology 74: 1039-1050.

97. Griffith SC (2019) Cooperation and coordination in socially monogamous birds: Moving away from a focus on sexual conflict. Frontiers of Ecology and Evolution 7: 455.

98. Kingma SA, Hall ML, Arriero E, et al. (2010) Multiple benefits of cooperative breeding in purple-crowned fairy-wrens: A consequence of fidelity? J Anim Ecol 79: 757-768.

99. Teunissen N, Kingma SA, Hall ML, et al. (2018) More than kin: Subordinates foster strong bonds with relatives and potential mates in a social bird. Behavioral Ecology 29: 1316-1324.
100. Bates LA, Lee PC, Njiraini N, et al. (2008) Do elephants show empathy? Journal of Consciousness Studies 15: 204-225.

101. F Péron, L Rat-Fischer, M Lalot, et al. (2011) Cooperative problem solving in African grey parrots (Psittacus Erithacus). Anim Cogn 14: 545-553.

102. Jelbert SA, Singh PJ, Gray RD, et al. (2015) New Caledonian crows rapidly solve a collaborative problem without cooperative cognition. PLoS One 10: e0133253.

103. Heaney M, Gray RD, Taylor AH (2017) Keas perform similarly to chimpanzees and elephants when solving collaborative tasks. PLoS One 12: e0169799.

104. Schwing R, Jocteur E, Wein A, et al. (2016) Kea cooperate better with sharing affiliates. Anim Cogn 19: 1093-1102.

105. Torres OS, Castro AC, Balsby TJS, et al. (2020) Problem-solving in a cooperative task in peach-fronted conures (Eupsittula aurea). Animal Cognition 23: 265-275.

106. Ostojić L, Cheke LG, Shaw RC, et al. (2016) Desire-state attribution: Benefits of a novel paradigm using the food-sharing behavior of Eurasian jays (Garrulus glandarius). Commun Integr Biol 9: e1134065.

107. Numan M, Young LJ (2016) Neural mechanisms of motherinfant bonding and pair bonding: Similarities, differences, and broader implications. Horm Behav 77: 98-112.

108. Acevedo BP, Aron A, Fisher HE, et al. (2012) Neural correlates of long-term intense romantic love. Soc Cogn Affect Neurosci 7: 145-159.

109. Ross HE, Young $L$ (2009) Oxytocin and the neural mechanisms regulating social cognition and affiliative behavior. Front Neuroendocrinol 30: 534-547.

110. Hurlemann R, Patin A, Onur OA, et al. (2010) Oxytocin enhances amygdala-dependent, socially reinforced learning and emotional empathy in humans. J Neurosci 30: 4999-5007.

111. Kirsch P, Esslinger C, Chen Q, et al. (2005) Oxytocin modulates neural circuitry for social cognition and fear in humans. J Neurosci 25: 11489-11493.

112. Feldman R, Zagoory-Sharon O, Maoz R, et al. (2012) Sensitive parenting is associated with plasma oxytocin and polymorphisms in the oxytocin receptor (OXTR) and CD38 genes. Biol Psychiatry 72: 175-181.

113. Schneiderman I, Zagoory-Sharon O, Leckman JF, et al. (2012) Oxytocin during the initial stages of romantic attachment: Relations to couples' interactive reciprocity. Psychoneuroendocrinology 37: 1277-1285.

114. Duque JF, Leichner W, Ahmann H, et al. (2018) Mesotocin influences pinyon jay prosociality. Biol Lett 14: 20180105.

115. Pan Y, Cheng X, Zhang Z, et al. (2017) Cooperation in lovers: An fNIRS-based hyperscanning study. Hum Brain Mapp 38: 831841.

116. Hall ML, Peters A (2008) Coordination between the sexes for territorial defence in a duetting fairy-wren. Animal Behaviour 76: 65-73.

117. Dahlin CR, Benedict L (2014) Angry birds need not apply: A perspective on the flexible form and multifunctionality of avian vocal duets. Ethology 120: 1-10.

118. Hall ML, Magrath RD (2007) Temporal coordination signals coalition quality. Curr Biol 17: 406-407. 
Citation: Kaplan G (2020) Long-Term Attachments and Complex Cognition in Birds and Humans are Linked to Pre-Reproductive Prosociality and Cooperation. Constructing a Hypothesis. Ann Cogn Sci 4(1):127-142

119. Brumm H, Slater P (2007) Animal communication: Timing counts. Curr Biol 17: 521-523.

120. Lorenz K (2002) On aggression. Psychology Press.

121. Lorenz K (1931) Beiträge zur Ethologie sozialer Corviden. Journal für Ornithologie 79: 67-127.

122. Koboroff A, Kaplan G, Rogers LJ (2013) Clever strategists: Australian magpies vary mobbing strategies, not intensity relative to different species of predator. Peerj 1: e56.

123. Hogg MA, Turner JC (1985) Interpersonal attraction, socia identification and psychological group formation. European Journal of Social Psychology 15: 51-66.

124. Sharrock R, Day A, Qazi F, et al. (1990) Explanations by professional care staff, optimism and helping behaviour: An application of attribution theory. Psychol Med 20: 849-855.

125. Schuett W, Dall SR, Royle NJ (2011) Pairs of zebra finches with similar 'personalities' make better parents. Animal Behaviour 81: 609-618.

126. Ihle M, Kempenaers B, Forstmeier W (2015) Fitness benefits of mate choice for compatibility in a socially monogamous species. PLoS Biol 13: e1002248.

127. Both C, Dingemanse NJ, Drent PJ, et al. (2005) Pairs of extreme avian personalities have highest reproductive success. Journal of Animal Ecology 74: 667-674.

128. Griffith SC, Pryke SR, Buttemer WA (2011) Constrained mate choice in social monogamy and the stress of having an unattractive partner. Proc Biol Sci 278: 2798-2805.

129. Gabriel PO, Black JM (2013) Correlates and consequences of the pair bond in Steller's jays. Ethology 119: 178-187.

130. Ouyang JQ, van Oers K, Quetting M, et al. (2014) Becoming more like your mate: Hormonal similarity reduces divorce rates in a wild songbird. Animal Behaviour 98: 87-93.

131. Bastock M (2018) Courtship: An ethological study. Routledge.

132. Wachtmeister CA, Enquist M (2000) The evolution of courtship rituals in monogamous species. Behavioral Ecology 11: 405410.

133. Teitelbaum CS, Converse SJ, Mueller T (2017) Birds choose long-term partners years before breeding. Animal Behaviour 134: $147-154$
134. Hayashi M, Matsuzawa T (2017) Mother-infant interactions in captive and wild chimpanzees. Infant Behav Dev 48: 20-29.

135. Lambert ML, Massen JJM, Seed AM, et al. (2017) An 'unkindness' of ravens? Measuring prosocial preferences in Corvus corax. Animal Behaviour 123: 383-393.

136. Hamann K, Warneken F, Greenberg JR, et al. (2011) Collaboration encourages equal sharing in children but not in chimpanzees. Nature 476: 328-333.

137. Samuni L, Preis A, Mielke A, et al. (2018) Social bonds facilitate cooperative resource sharing in wild chimpanzees. Proc Biol Sci 285: 20181643.

138. Guo $Q$, Sun $P$, Cai M, et al. (2019) Why are smarter individuals more prosocial? A study on the mediating roles of empathy and moral identity. Intelligence 75: 1-8.

139. Clutton-Brock T (1991) The evolution of parental care. Princeton University Press, Princeton, NJ, USA.

140. Kaplan G (2017) Babbling in a bird shows same stages as in human infants: The importance of the 'Social' in vocal development. Trends in Developmental Biology 10: 97-123.

141. Karten HJ (2015) Vertebrate brains and evolutionary connectomics: On the origins of the mammalian 'neocortex'. Philos Trans R Soc Lond B Biol Sci 370: 20150060.

142. Gebauer JE, Riketta M, Broemer P, et al. (2008) Pleasure and pressure based prosocial motivation: Divergent relations to subjective well-being. Journal of Research in Personality 42: 399-420.

143. Dougherty LR (2020) Designing mate choice experiments. Biological Reviews 95: 759-781.

144. Ten Cate C, Vos DR (1999) Sexual imprinting and evolutionary processes in birds: A reassessment. In: PB Slater, JS Rosenblat, CT Snowden, et al. Advances in the Study of Behavior. (edn) Academic Press, San Diego, 28: 1-31.

145. Nowicki S, Peters S, Podos J (1998) Song learning, early nutrition and sexual selection in songbirds. American Zoologist 38: 179-190.

146. Fraser ON, Bugnyar T (2010b) Do ravens show consolation? Responses to distressed others. PLoS ONE 5: e10605.

DOI: $10.36959 / 447 / 347$

Copyright: (C) 2020 Kaplan G. This is an open-access article distributed under the terms of the Creative Commons Attribution License, which permits unrestricted use, distribution, and reproduction in any medium, provided the original author and source are credited. 